\title{
O Que Chamamos de Performance?
}

AGRA, Lucio ${ }^{1}$

Hans Eijkelboom, Bas Jan Ander, Jirí Kovanda, Sigurdur Gudmunssun, Techching Hsieh, Robert Filiou, Alan Kaprow. Resumidamente, seriam esses os sete nomes que, na $30^{\mathrm{a}}$ Bienal Internacional de Artes de São Paulo (2012) representam a performance. Não necessariamente, claro, pois o primeiro artista é um fotógrafo que se interessa, neste momento de sua obra, pelo comportamento dos seres humanos comuns da rua e a forma como seus corpos carregam uma fôrma do vestir "pret-à-porter". Os brasileiros Sofia Borges e Rodrigo Braga responderiam pelo que mais diretamente pode ser creditado a uma ação do corpo em presença, embora se trate em ambos os casos, novamente, de artistas plásticos que lançam mão - seja pela fotografia, seja pelo vídeo - de estratégias de registro que os levam diante do púbico, enquanto corpos.

Na esfera dos históricos, Allan Kaprow e Robert Filiou equilibram dois extremos do happening (visadas estadunidense e europeia). E, muito embora o ar "performático" habite a exposição inteira, quanto mais se considerarmos a proposta curatorial, "A iminência das poéticas", ainda assim trata-se a performance com um certo "cuidado distante" como se a sua presença - tão definitivamente declarada na Bienal "do vazio" - agora carecesse de uma discussão sobre a sua pertinência, ontologia, denominação.

Não pega muito bem ater-se a etiquetas. Não parece conveniente fazer supor que haja territórios definidos em tempos do uso quase kitsch do termo "desterritorialização". Decerto esta existe mas naturalmente convém esquecer que o autor da formulação desse conceito insiste, por diversas vezes, que ela implica necessariamente e todas as vezes em uma "reterritorialização".

Não estou criticando negativamente a curadoria da Bienal, pelo contrário, até mesmo entendo que ela flagra com muita pertinência o momento que vivemos. Interessa-me, por outro lado, meditar aqui sobre essa transição da afirmação decidida do termo/linguagem para a decidida incorporação e simultâneo cuidado ao mencionar "performance", isto é, interessa-me a "batata quente" como forma de entrarmos em uma discus-
Lucio Agra, natural de Recife (PE), cresceu no Estado do Rio de Janeiro e, há 17 anos, vive e trabalha em São Paulo. Sua produção artística mescla a poesia, a performance, a música e as tecnologias. Também é professor de performance na Graduação em Comunicação das Artes do Corpo da PUC$\mathrm{SP}$, mesma instituição na qual doutorou-se em Comunicação e Semiótica com a tese Monstrutivismo - reta e curva das vanguardas, recentemente publicada (Ed. Perspectiva, 2010). Prepara novo livro sobre a performance no contemporâneo.

Nota:

Quero assinalar meu agradecimento a

algumas pessoas que contribuíram, de uma forma ou de outra, para as formulações desse texto, ainda um início de pesquisa. A Grasiele Sousa pelas sugestões e acompanhamento atento. A Suely Rolnik pelas sugestões contidas em alguns ensaios e palestras recentes. Aos meus alunos da matéria "Tópicos Avançados em Performance" por terem contribuído para este breve começo de investigação. E a Marcos Bulhões pela sugestão para lá de interessante. 
são mais ampla que esse texto quer buscar, a conversa sobre "o que chamamos de performance". Essa terceira pessoa do plural somos nós, no Brasil. É bom frisar pois há diferenças em relação a outros "nós" como os da Latino-América, das Américas, e do mundo ocidental.

Para ajudar a pensar isso, sugiro dois outros episódios aparecidos na mídia há pouco tempo:

- a crítica da Folha de São Paulo comentando a mais recente edição da Mostra Verbo da Galeria Vermelho, agora espalhada ao longo do ano em dias específicos. Nesse mês de outubro a edição do evento apresentou performances que o articulista avaliou como um "retorno ao teatro".

- De outro lado, chegou-me às mãos um artigo do antropólogo Hermano Vianna, na sua coluna de O Globo de 27 de julho de 2012, no qual discute, sob o título "Ocidentais", o estranho caso de sermos entendidos, na Europa, como sendo Orientais.

Começo pelo segundo: o artigo rememora uma outra ocasião, ainda nos anos 80, quando o articulista teve pela primeira vez contato com o que lhe pareceu então uma ideia esdrúxula: os antigos "países periféricos", não tão obviamente "orientais" (como aqueles que compõem, por exemplo, a América do Sul), foram chamados, na exposição Les magiciens de la terre, com a curadoria de Jean-Hubert Martin, de "orientais". Naquela oportunidade, diz o autor, ele teria se rebelado violentamente contra uma ignorância europeia a nosso respeito. Mas, passados mais de dez anos, elogia a postura do artista Ernesto Neto. Este, ao invés de reagir com estranhamento a uma pergunta da curadora que o levava a uma exposição nos países nórdicos, preferiu a curiosidade. A pergunta era como ele se sentia expondo pela primeira vez no Ocidente. Neto teria perguntado o que era o Ocidente para ela e em seguida por que achava que éramos orientais. À segunda pergunta, ela respondeu: "porque vocês são sensuais". (VIANNA, 2012)

No primeiro texto se comentam as performances de outubro da Mostra Verbo da Galeria Vermelho, que pareciam-se mais com Teatro do que com performance, na visão do articulista. Ou, melhor dizendo, talvez quisesse formular uma hipótese, logo seus comentários eram todos - por assim dizer - "dobrados" no sentido de favorecer a ideia central do artigo. Conheço o trabalho de Vivian Cacuri - para citar apenas um dos artistas comentados - e sei que tradicionalmente trabalha com o que costumamos chamar "performance sônica". Ou, dito de outra forma, todos os trabalhos parecem ter a característica comum a qualquer performance que é um resquício por menor que seja do teatro. Entretanto nenhum me pareceu, nem sequer pela 
descrição do jornalista, ter a menor relação ou representar o que se chamaria uma "volta ao teatro". Meu argumento aqui, mais uma vez, não deseja necessariamente se contrapor à matéria, mas refletir sobre este desejo de encontrar algum processo de "reterritorialização" (talvez, mais precisamente e ainda segundo Deleuze, de "recognição") da performance em direção a uma suposta origem. O título da matéria já oferece uma dica: "Verbo reúne performances com ar teatral" (MARTÍ, 2012).

Vejo uma interessante semelhança em contraste entre estes textos. Se, por um lado, Hermano Vianna quer afirmar a diferença como potência, revendo seu anterior ponto de vista e colocando a possibilidade de um certo "Oriente do Ocidente", também sugere, por outro lado, que esta diferença nunca esteve muito clara para nós. Enquanto buscávamos nas artes, por exemplo, a crítica a uma suposta inevitável inserção na linhagem ocidental, mal sabíamos termos sido, há muito tempo, postos na estante dos que são vistos sempre com um misto de fascinação e receio. Um certo tipo de oriental, cuja utopia de um trans-exotismo, de uma ultrapassagem dos estereótipos, fosse finalmente realizável, por ter sido o "colonizador", ele mesmo, que inadvertidamente abriu essa possibilidade. (VIVEIROS DE CASTRO, 2012:182 e ss.)

No primeiro texto, uma preocupação de diagnosticar qual seria o último esforço de sintonia com o "panorama artístico atual" (leia-se mercado ocidental de arte) faz com que se descubra, pari-passu com o que se produz internacionalmente, um retorno ao teatro como fonte "primária" da performance. Certo esforço por "contrariar o santo": quando todos já deveriam esperar o fim do teatro, eis que ele surge novamente, firme e forte, interferindo no "meio" das artes visuais.

Vejo que - e esta é certamente uma opinião muito pessoal - o que o primeiro texto faz é esforçar-se por estar de acordo com o que seria uma atitude "crítica" e o segundo tenta pensar também criticamente mas de forma um pouco mais próxima dos afetos envolvidos na questão. O segundo busca uma atitude "clássica", por assim dizer, em um pensamento crítico: wit, fina ironia, distanciamento. No primeiro tudo se passa com o próprio autor confessando abertamente sua mudança de posição diante do problema. No segundo o problema é visto "objetivamente", com um olhar que demonstra ser astuto o suficiente para não se "envolver" com a proposta ou, talvez, revelar algo que supostamente não era percebido nem sequer pelos próprios artistas...

Gostaria, pois, de pegar estas duas atitudes como exemplares do modo como nos relacionamos com a arte contemporânea e com a performance, em particular, no Brasil. E, assim fazendo, 
contrastá-las com um texto de um dos pioneiros da dança do século 20, Klauss Vianna que, em um artigo de 1952, intitulado "Pela criação de um balé brasileiro", iniciava dessa forma:

\footnotetext{
"Um grande movimento renovador tem-se realizado ultimamente dentro do teatro brasileiro abrangendo todos os seus setores: direção, interpretação, escolha de argumentos, decoração etc... Grupos de amadores e de universitários empreendem realizações tão arrojadas que há poucos anos dir-se-ia impossível a sua realização. Há platéia compensadora para todos esses empreendimentos e os lucros colhidos atestam a segurança da iniciativa." (VIANNA, 1952:1)
}

O diagnóstico inicial pode fazer pensar que haveria um novo movimento, baseado em grupos, que estaria a produzir a legítima renovação do teatro brasileiro. Não é esse o objetivo do autor. Veja-se o segundo parágrafo, na sequência:

\footnotetext{
"Não podemos considerar a existência de um teatro brasileiro propriamente dito, mas é de se esperar que dentro de pouco tempo venhamos a consegui-lo; as novas agremiações profissionais e de amadores que se multiplicam, as escolas que se fundam, o aparecimento recente de uma crítica nacional esclarecida, e as peças de valor que alguns de nossos escritores tem produzido, tudo isso virá certamente ter como fim o aparecimento do teatro brasileiro com características próprias." (VIANNA, 1952:1)
}

Uma estranha guinada na argumentação acontece repentinamente, já a partir da enunciação contida na primeira frase. É ela que desmente a impressão anterior e põe as coisas no lugar com uma afirmação que hoje seria considerada completo exagero. Naturalmente. A época em que o articulista-coreógrafo escreve conclama os artistas em nome do surgimento de alguma "identidade brasileira".

"O aparecimento recente de uma crítica nacional esclarecida" é obviamente uma frase forte que afirma com todas as letras um possível "deserto" anterior. O alvo é o "aparecimento do teatro brasileiro com características próprias". É uma fala inaugural, não uma abertura de novos tempos, mas do tempo.

Convido o leitor para o terceiro parágrafo, de onde pretendo desenvolver meus argumentos:

\footnotetext{
"Entretanto, se atentarmos para um outro setor da arte cênica, o ballet, notaremos que a situação é exatamente diferente: aí impera uma desorganização quase que completa e a desagregação mesmo do trabalho já conseguido. Há falta de platéia para o ballet? Não. Algumas iniciativas como a do Ballet da Juventude do sr. Igor Schetzoff demonstraram cabalmente a existência de um grande público para esta arte, ou seja, a mesma platéia do nosso teatro chamado de 'clichê'.' (VIANNA, 1952:1)
} 
A sequencia imediata é a "identificação das origens" do problema, que Vianna enxerga no "próprio ballet" feito aqui com "falta de originalidade, de qualidade íntima". Sabemos, apesar da imprecisão, onde ele quer chegar. O traço distintivo, a diferença seria o que nos faz falta, a dificuldade, em outras palavras, de olharmos para nós mesmos, traídas até pelo autor com a sua insistência no uso do termo balé grafado em francês.

Alguém há de lembrar que faz falta a noção de antropofagia, o que é real. Por essa época, o desprestígio cabal da figura de Oswald de Andrade abatido, doente e endividado, visto como quase um "charlatão" do modernismo, não permitiria vislumbrar o que, no entanto, se tornou claro em 1967, com a montagem do Rei da Vela, pelo Oficina. O tom incomodamente anacrônico do texto de Klauss que, insistimos, colocava uma questão que estava no centro do debate da época, rescende a partir desse contraste que pouco mais que dez anos produzem como resultante de um impacto modificador que toda a cultura - brasileira e internacional - experimentou como uma reviravolta.

Mas falta também, o que parece grave, um teatro legítimo, segundo o autor. E ele mesmo aponta uma crítica violenta a uma dança de cópia, sem personalidade. 30 anos antes a Semana de Arte Moderna lançava os argumentos dos modernistas em relação ao nosso atavismo francês, queixa que de que ecoa no artigo de Vianna. 15 anos mais tarde, o Brasil moderno, pós-modernista como já queria Mário Pedrosa, se apresentará em perfeita consonância com um movimento internacional de renovação teatral, cinematográfica, etc. Aquele diagnóstico pessimista não deixa adivinhar o que poderia ser visto como perspectiva, se lemos apenas o primeiro parágrafo.

Sugiro que pensemos nessa contradição - ou se quiserem, ambiguidade - como uma oscilação típica de nosso pensamento sobre a cultura desde a arrancada desenvolvimentista. A crise da noção de identidade e a busca de um caminho que falava à altura do que se produzia para fora da "casca de caracol" brasileira, só se dá no contexto desses 15 anos, sobretudo na contestação de base do que ficou resumido em torno da imagem do Tropicalismo (tento pensar menos no movimento deflagrado na mídia como estratégia, ao mesmo tempo irônica e mercadológica, e muito mais sobre o zeitgeist que ele fez propagar).

$\mathrm{O}$ artigo de Klauss Vianna teve um efeito de choque em mim que venho escrevendo sucessivos textos em defesa da performance feita no Brasil, de sua existência como linguagem e da recusa em faze-la naufragar na torrente de argumentos negativos sobre o seu nome, sua pertinência, etc. Uma argu- 
mentação contra o que costuma acontecer, como o que descrevi acima em relação à Bienal. De forma discreta, ou não se fala da performance ou é quase como se ela não pudesse existir, embora venha insistindo em aparecer há muito anos por aqui.

A resposta ao choque de ver essa argumentação repetir, ao seu modo, a mesma perplexidade de 52, só foi possível quando passei a indagar algo semelhante ao que Liliana Coutinho pergunta, no interessante ensaio introdutório do número 3 da revista portuguesa Marte : "Do que falamos quando falamos de performance?" Repito a pergunta em tom brasileiro: O que chamamos de performance no Brasil?

A resposta é bem mais fácil no que diz respeito ao Teatro e à Dança. Artes milenares, diante de suas tradições é preciso compreender o que significa, por exemplo, a implantação devida ao ritual da Primeira Missa.

Mas bem mais complexo seria, conforme assinalou outro dia o Prof. Marcos Bulhões, em uma conversa informal, se ao invés de tomarmos essa origem reclamássemos os rituais dos índios ou dos negros escravizados. Aí talvez, de uma perspectiva antropológica, é onde começa nossa performance. É onde se daria uma possível "iminência" de novas poéticas. Brasileiras.

Podemos também adotar outro caminho: entender a performance no Brasil a partir do que seria um "cânon" de origem. Esse é o caso do consenso histórico que vem transitando nos debates sobre essa arte no Brasil, fixando-se, quase sempre, em torno à figura de Flávio de Carvalho (1899-1973), cuja singularidade e proximidade aos procedimentos conhecidos internacionalmente como processos "da performance" ou "performáticos" poderiam credenciá-lo como o mentor desta arte no País. (AGRA, 2012)

Se, entretanto, propusermos outra noção, mais radical e mais próxima da história anterior à colônia, como sugere o Prof. Bulhões, então Flávio - que concordaria certamente com essa antecipação - seria precedido por uma inestimável genealogia de rituais indígenas da qual sabemos pouco e que a Antropologia dos últimos cem anos vem tentando salvar do esquecimento.

A seus modos, as duas opções são acenos seja à instituição Arte/Mercado da Arte, seja a da Ciência/Academia. O que me interessa sustentar aqui é a forma de produção da performance que não é necessariamente arte para nenhum dos dois universos e que, entretanto, prossegue sendo para um terceiro, o da cultura "popular urbana" ou aquilo que, apropriadamente, Jerusa Pires Ferreira vem chamando de "cultura das bordas" (FERREIRA, 2010)

Para esse lugar, entendido como reversão da ideia de mar- 
ginalidade ou "periferia" - pois negocia o ir e vir da informação entre os antigos referenciais da centralidade cultural e das margens - confluem práticas artísticas que as mídias em geral e a televisão em particular saíram na frente e souberam traduzir para si mesmas.

Do circo e do circo-teatro vieram diversos humoristas como Costinha, Zé Bonitinho, e outros artistas com menor ou maior grau de bizarria. Foram foco do interesse do cinema alcunhado de "marginal" do início dos anos 70 que, sob a severidade da ditadura, construiu um discurso imagético-experimental que se valia do escracho dos humoristas revelados pela chanchada dos anos 50 e transportados à televisão, condenados à infindável repetição das mesmas gags.

A conexão entre os humoristas do tipo stand-up (hoje um gênero revertido sobre seu próprio estereótipo) como José Vasconcelos e, no caso americano, Ernie Kovacs e, mais claramente, Lenny Bruce, é evocada diversas vezes pelos artistas e estudiosos da performance. Tenho sugerido o livro de Max Gordon Ao vivo no Village Vanguard (GORDON, 2006), um relatório das memórias do autor sobre a legendária casa noturna de Nova York, como uma bibliografia da performance justamente porque descreve - às vezes com minúcia - um show business underground cuja memória, depois levada à TV, alimentou o imaginário de vários artistas do Fluxus americano e de outros posteriores (sobretudo nos anos 80).

Mas no Brasil pode causar surpresa a evocação de figuras como Zé Bonitinho - com uma participação intensa nos filmes mais experimentais do Sganzerla dos anos 70 - como artista fundamental da performance. O mesmo se pode dizer, indo mais longe, da longa atuação dos jurados de programas de calouros, como Pedro de Lara ou Elke Maravilha.

As informações corporais/criativas de um Chacrinha (cuja ação emerge do circo e do rádio), de Carmen Miranda, de astros e estrelas excêntricos em maior ou menor medida, de Jards Macalé a Cauby Peixoto, de Moreira da Silva a Serguei; a exploração radiante da diferença em Daminhão Experiença, Jayme Figura ou Artur Bispo do Rosário são, em sua óbvia diversidade, pontos luminosos que exprimem caminhos da performance no Brasil sem que necessariamente seja dela que se trate, enquanto denominação caucionada pelo mercado artístico, pela crítica, pelo público especializado.

Tratar-se-ia, antes de mais nada, de produzir o desrecalque da nossa posição colonizada que nos impinge a ideia de que todos esses artistas nada teriam a nos dizer e pertencem tão somente ao ridículo transe da mídia.

Propositalmente misturei o que seriam "alhos" e "buga- 
lhos". Nas faixas de prestígio, artistas multimídia com forte carga "performática" como Tom Zé ou Jards Macalé, Sérgio Sampaio ou Raul Seixas, Ney Matogrosso ou Glauber Rocha transitam por esferas de prestígio para as quais pode ser possível aceitar Wilson Grey mas não Wilza Carla, Walter Franco ou Luz del Fuego mas não o Profeta Gentilezza (não aí), Edy Star ou a reacionária Dercy Gonçalves. Já é possível aceitar José Mojica Marins como cult mas ainda fica de fora o machismo tosco de Zé Trindade ou Falcão, o desabrido sexismo de Rita Cadillac ou a esculhambação de Tiririca e o "beijoqueiro".

Entretanto, foi nesse ambiente midiático onde todos transitaram - e não em qualquer outro - que os artistas brasileiros da performance "cresceram e se desenvolveram". Retomando a ideia de Hermano Vianna da possível positivação de um Ocidente a Oriente do Ocidente, ou levando a mesma noção para um passeio junto ao "falar menor" que Deleuze foi buscar em Kafka, suspeito que estamos deixando de lado a própria compreensão de nós mesmos quando falamos da cena - em geral - e da performance, em particular, no Brasil.

Gostaria de insistir na pergunta e não no gesto de afirmação. Os parágrafos acima formulam uma hipótese que podemos resumir nos termos: o que não percebemos que possa ser visto pela performance (Schechner: "tudo é performance se puder ser lido como performance") ou que sua forma de atuar/ver, neste país, não consegue enxergar?

Gostaria de articular a hipótese de inclusão dos artistas reunidos nesta visão "profana" com outra: a percepção que temos de nós mesmos como expressão cultural que ainda vive assombrada pelo medo.

Ainda mimetizamos comportamentos críticos cujo processo de legitimação dos objetos avaliados necessita sempre passar pela prova da metrópole. É justamente - voltando aos primeiros textos jornalísticos comentados neste ensaio - o que diferencia a leitura do crítico de arte da Folha, Silas Martí, do colunista de O Globo, Hermano Vianna, para além de todas as óbvias e possíveis diferenças: de tema, de abordagem, de finalidade. Ou seja, aqui me interessa destacar em que posição relativa se situam esses dois discursos. Martí busca imediatamente o subsídio da produção dos grandes centros (Moma, Documenta de Kassel) para justificar o que lhe pareceu uma guinada no panorama costumeiro de uma mostra de performance em São Paulo. O que o orienta é a confirmação, a partir dos centros de referência europeus/norte-americanos, da validade do estranho procedimento que vê se revelar na mais recente edição da mostra brasileira e que, não por acaso, inclui a presença de artistas trazidos da metrópole (um dinamarquês, um francês). 
O que orienta o pensamento de Vianna, Hermano é a presença de um brasileiro na metrópole, um desafio em si mesmo. Mas não é apenas isso, importa a versão europeia do olhar sobre o Brasil, construindo para nós e para eles uma diferença incompreensível.

Já o artigo do Vianna, Klauss, funciona como testemunho histórico por contraste que nos apresenta a gravidade da ferida colonial e o esforço de sua superação. $O$ gesto heroico do artista-articulista que luta para fazer ver aos seus leitores um fato real não percebido. Uma existência não reconhecida.

Entre essas forças que privilegiam consonâncias ou divergências, está, do meu ponto de vista, ancorado o debate da cultura brasileira em geral e, naturalmente, como fala devorada, reaprendida, transformada e antecipada/adivinhada pela cultura das bordas, a fala da performance.

Foi a partir desse entendimento que iniciamos uma pesquisa que venho coordenando e promovendo, nascida de uma das matérias do currículo da área de performance da Graduação em Comunicação das Artes do Corpo da PUC-SP, onde sou professor.

O curso se chamava "Tópicos Avançados de Performance" e encaminhamos o seu direcionamento para a investigação da produção artística brasileira nesse campo. Buscar a genealogia dessa prática na cultura brasileira foi logo tornando evidente uma particularidade do dilema geral em torno à própria denominação. E, partindo da problematização de Liliana Coutinho ("De que falamos?”) chegamos à pergunta que dá título a este ensaio.

As respostas, os alunos foram buscar em diversos lugares que eles mesmos escolheram: nas imagens fotográficas/registros de performances brasileiras sobre as quais, projetadas em escala humana, dançou a aluna Dora Selva; nas relações iniciais entre a antropofagia e a performance que Carolina Castanho, atriz do Teatro Oficina, busca entender em vista da construção da Universidade Antropofágica na qual se empenha; na presença - nomeada ou não - da performance nas ações de rua, lugar do funcionamento de todo o universo popular no Brasil e nos Orientes, Sul, etc como investiga Diego Marques; na busca da antecipação da própria performance na obra de Flávio de Carvalho, como na pesquisa do ator e performer Rafael Mendes; como palavra-chave encontrável na série de Bienais, desde a primeira até hoje, buscada por Marco Biglia com rigor estatístico; e, da mesma forma, pelo ator e performer Affonso Lobo, nos programas de fomento ao Teatro da Prefeitura de São Paulo, iniciados na primeira década do século 21.

A pesquisa vem revelando alguns dados surpreendentes: a oscilação do entendimento do que seja performance a partir das diferentes bienais, com aparições pioneiras. A mesma osci- 
lação perceptível no Fomento com características naturalmente diversas, tendo que ver com certo desejo de inclusão num vocabulário "novo". A reavaliação de artistas como performers, de João do Rio a Oswald de Andrade e Flávio de Carvalho. A reavaliação do trânsito da performance, ela mesma, no processo evolutivo da arte brasileira.

A pergunta do título deste texto assinala o início da pesquisa. O que vai surgindo demonstra uma história do descrédito de nós mesmos, o quanto nos desconhecemos. Ao mesmo tempo, chama a atenção o quanto já se produziu nesse campo no Brasil. E como a cultura brasileira ignora, ainda, essa produção.

Rastreá-la pode ajudar-nos a entender a própria busca. Na ambiguidade do título também está a desejável incerteza de nosso próprio juízo sobre a performance no Brasil e em um curso onde ela se discute. Tal incerteza ou instabilidade é justamente o que nos interessa para a mutação permanente do conceito que esta palavra mobiliza. Se não pudéssemos deslocar a performance do lugar onde ela se enuncia como origem ocidental, não poderíamos pensar em sua derivação como a verdadeira busca de diferença que parece ter sido o combustível que vem movendo sua máquina até aqui. 


\section{REFERÊNCIAS BIBLIOGRÁFICAS}

AGRA, Lucio (2012). "Maldito polimorfo na dança do comichão" in PENTEADO, F. M. e GATTI, José (orgs). Masculinidades teoria, crítica, artes. São Paulo, Estação das Letras e Cores.

COUTINHO, Liliana (2008). De que falamos quando falamos de performance, in MARTE no. 3. Lisboa, Associação dos Estudantes de Belas Artes, Universidade de Lisboa.

FERREIRA, Jerusa P. (2010). Cultura das bordas. SP, Ateliê.

GORDON, Max (2006). Ao vivo no Village Vanguard SP. Cosac \& Naify, tradução de Cid Knipel Moreira.

MARTINS, Heitor et al. Guia da exposição - Trigésima Bienal de São Paulo - A iminência das poéticas. São Paulo, Fundação Bienal, 2012.

MARTI, Silas (2012). Verbo reúne performances com ar teatral. in Folha de São Paulo - Ilustrada SP, Folha, 2/10/2012.

SCHECHNER, Richard (2006). Performance Studies - an introduction. London/NewYork, Routledge (2 $2^{\mathrm{a}}$ edição).

VIANNA, Hermano. Ocidentais. in O GLOBO, segundo caderno. Rio, 27 de julho de 2012.

VIANNA, Klauss. "Pela criação de um balé brasileiro". in revista Horizonte, outubro de 1952, disponível em http://www. klaussvianna.art.br/acervo.asp\#[showDet 1878

VIVEIROS DE CASTRO, Eduardo (2012). "O mármore e a murta: sobre a inconstância da alma selvagem" in A inconstância da alma selvagem - e outros ensaios de antropologia. SP, Cosac \& Naify. 